\title{
Compact Planar Ultra-wideband Antennas with Continuously Tunable, Independent Band-Notched Filters
}

\author{
Ming-Chun Tang, Senior Member, IEEE, Hao Wang, Tianwei Deng, Student Member, IEEE, and \\ Richard W. Ziolkowski, Fellow, IEEE
}

\begin{abstract}
A compact planar ultra-wideband (UWB) antenna with continuously tunable, independent band-notches for cognitive radio applications is presented. The antenna is fabricated using a copper cladded substrate. A radiating patch with an inverted rectangular $T$-slot is etched on the top side of the substrate. A straight rectangular strip with a complete gap is embedded into the T-slot. By placing a single varactor diode across this gap, a frequency-agile band-notch function below 5 $\mathrm{GHz}$ is realized. On the bottom side of substrate, a U-shaped parasitic element having an interdigitated-structure is placed beneath the radiating patch. The second narrow band-notch is created by inserting a second varactor diode into the gap on one leg of the parasitic element. It has a frequency agile performance above $5 \mathrm{GHz}$. The presence of the interdigitated structure suppresses higher-order resonant modes and enhances the tunability of the notched bandwidth. Because these antenna structures naturally block DC, a very small number of lumped elements are required. The experimental results, which are in good agreement with their simulated values, demonstrate that both band-notches can be independently controlled and the entire frequency-agile fractional bandwidth is as high as $\mathbf{7 4 . 5} \%$, demonstrating a very wide notched frequency-agile coverage.
\end{abstract}

Index Terms-Band-notch filters, frequency agile, frequency tunable, planar antennas, UWB antennas

\section{INTRODUCTION}

$\mathrm{U}$ ltra-wideband (UWB) technology has been widely applied in wireless sensor networks, biomedical and healthcare wireless systems, and some other in-house devices in radar detecting, locating, and communications [1]. These applications benefit from the unique features of low-power spectral density and consumption associated with UWB

Manuscript received on Oct. 12, 2015; revised on Mar. 09, 2016, Accepted on May 07, 2016.

This work was supported in part by the National Natural Science Foundation of China contract numbers 61471072, 61571069 and 91438104, and in part by the Fundamental Research Funds for the Central Universities contract number 106112015 CDJZR165510.

M. -C. Tang and H. Wang are with the College of Communication Engineering, Chongqing University, Chongqing, 400044, China (E-mail: tangmingchunuestc@126.com);

T. Deng is with the Department of Electrical \& Computer Engineering, National University of Singapore, 119077, Singapore;

R. W. Ziolkowski is with the Department of Electrical and Computer Engineering, University of Arizona, Tucson, AZ 85721 USA and with the Global Big Data Technologies Centre, University of Technology Sydney (UTS), Sydney, Australia (E-mail: ziolkowski@ece.arizona.edu). systems. Concurrently, a rapidly increasing number of licensed narrow-band wireless devices are sharing their operating frequency bands with the existing allocated UWB spectrum: 3.1-10.6 GHz. These include C-band satellite communication (3.7-4.2 GHz), WiMAX band (3.3-3.6 GHz), HIPERLAN/2 band $(5.15-5.35 \mathrm{GHz}, 5.470-5.725 \mathrm{GHz})$ and WLAN band (5.15-5.35 GHz, 5.725-5.825 GHz) systems. The overlaps of these bands with the UWB spectrum cause severe in-band interference and negatively impact the performance of UWB systems [2]. Consequently, one of the most popular solutions to this overlapping band problem is to introduce a variety of fixed single-, dual-, and multi-band notched filters into the UWB antennas to minimize this interference [3-6]. While effective, this fixed band-notch solution has an inherent drawback, i.e., the associated rejection-bands are permanent and cannot be dynamically adjusted when there is no interference encountered in one or more bands. Reconfigurable and frequency agile technologies pave an effective road for conquering this limitation [7].

Various examples of UWB antennas with reconfigurable and frequency agile band-notch characteristics have been reported over the last decade [8-34]. In general, these UWB antennas could be classified into the following two categories according to their tuning characteristics. On the one hand, the requirements of on-demand rejection over one (or more) fixed narrow frequency band(s) simply requires one (or more) band-notch region(s) to be switched between its (their) $\mathrm{ON}$ and OFF states. This strategy has been accomplished successfully by integrating ON/OFF switch-type active elements, such as p-i-n diodes [8-15], micro-electromechanical system (MEMS) switches [16-17], shorting circuits [18], stepper motors [19], and optically controlled microwave switches (OCMSs) [20-21], into these UWB antennas. On the other hand, embedding continuously tunable voltage or current elements, for instance, varactors [22-33], into similar UWB antennas empowers one's ability to continuously tune their band-notch frequency windows.

While both of these techniques provide the additional degree of freedom to dynamically tune the band-notch regions, they each have drawbacks that potentially restrict their applications in cognitive radio systems, particularly with respect to the aspect of efficient dynamic spectrum access and management $[35,36]$. Resorting to switch-type elements, one is only provided with the function of band-notch ON/OFF switching at fixed frequencies. One does not obtain any frequency-agile 
property to continuously shift those band-notch frequencies. To achieve dynamically-controlled band-notches over a wide portion of the UWB spectrum with this approach, one would have to incorporate several switches into the UWB antenna, each covering at least one discrete set of frequencies [8-21]. In contrast, employment of continuously-controllable elements does provide one with the ability to achieve the desired continuously-tunable frequency-agile band-notches. However, to the best of our knowledge, the UWB antennas with embedded varactors that have been reported to date have only achieved a single frequency-agile notch-band. In other words, at any one dynamical time, they only provide one notched-band [22-33]. They do not satisfy the cognitive radio requirements of being able to handle multiple band-notches at any one dynamical time. Consequently, it remains highly desirable to achieve one compact UWB antenna that would provide two or more independent, continuously-tunable frequency-agile band-notches, i.e., that would possess the means of creating multiple, continuously-tunable frequency-rejection bands at any stipulated dynamical time [8-33]. While two band-notches were shifted in [34] by embedding two passive capacitors with different values into the radiating patch of a UWB antenna, active tuning was not achieved in practice.

In this paper, a compact planar UWB antenna with two independent, frequency-agile band-notches is investigated numerically and experimentally. It could potentially serve as excellent candidate for cognitive radio systems owing to its real-time agility to allocate spectrum $[35,36]$. In Section II, an inverted T-slot is first introduced in the center of the radiating patch of a UWB monopole antenna. While it helps achieve a compact size, it also provides enough space for the band-notch structures. In Section III, two types of band-notch elements are introduced. A split straight rectangular strip and an interdigitated U-shaped parasitic element are embedded into the top and bottom sides of a copper-cladded substrate to create two different rejection-band elements. Varactors are inserted into these elements to enable their tunability. These two band-notch structures are organically combined to realize a new UWB antenna with two continuously-tunable band-notches. The simulated and experimental results confirm that both of these band-notches can be controlled independently and that their total frequency-agile fractional bandwidth coverage is as high as $74.5 \%$, a very wide gamut. Next, in Section IV, the design principles and physical mechanisms of the two frequency-agile band-notch structures are described in detail. Finally, some conclusions are drawn in Section V.

Note that all of the numerical simulations and their optimizations reported in this paper were performed using the frequency domain ANSYS/ANSOFT high frequency structure simulator (HFSS), version 13.0 [37].

\section{COMPACT Monopole UWB ANTENNA DESIGN}

The geometry of the baseline UWB monopole antenna used in the overall design process is illustrated in Fig. 1. Its optimized structural parameters are presented in Table I. This UWB antenna is to be constructed using standard printed circuit board (PCB) technology. It employs a Rogers Duroid 5880 substrate board, which has a relative permittivity $\varepsilon_{r}=2.2$, relative permeability $\mu_{r}=1.0$, and loss tangent $\tan \delta=0.0009$. Its overall size is only $34(\mathrm{~L}) \times 27(\mathrm{~W}) \times 0.787(\mathrm{~h}) \mathrm{mm}^{3}$. The thickness of copper film is $0.5 \mathrm{oz}(0.017 \mathrm{~mm})$. This monopole configuration is simple and has evolved from our previously reported printed planar UWB monopole antenna designs [3, 4, 38]. On the top side of the board material, a nearly rectangular radiating patch with an inverted $\mathrm{T}$-slot is positioned at the terminal of a microstrip feed line that has a $50 \Omega$ characteristic impedance (i.e., its width is $\mathrm{W}_{3}=2.4 \mathrm{~mm}$ ). On the bottom side, a conducting ground patch is designed with a much smaller, straight rectangular slot positioned at its upper edge to facilitate impedance matching. This additional rectangular slot effectively tunes the mutual coupling between the radiating and ground patches over a very large frequency range.

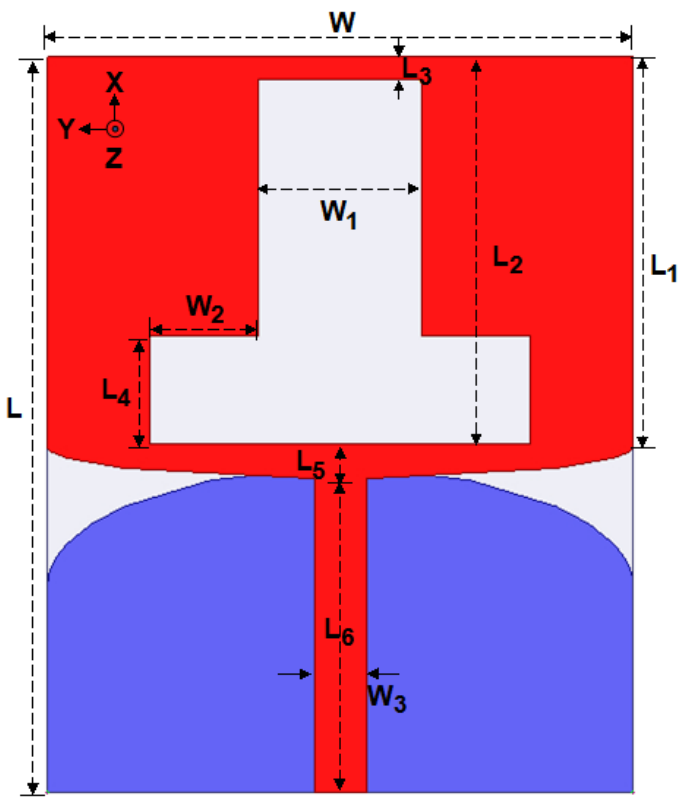

(a)

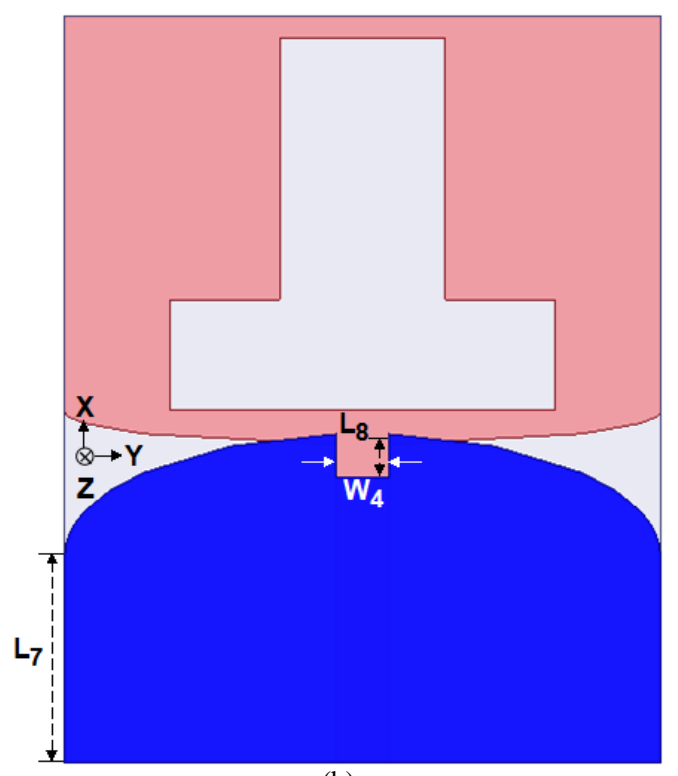

(b)

Fig. 1 Geometry of the UWB antenna with an inverted T-slot. (a) Top view, and (b) bottom view. 
The end of the microstrip-line strip and the lower edge of the ground patch are directly connected with a coaxial SMA connector to the $50 \Omega$ source. Note that although it is not depicted here, the SMA connector was included in the HFSS model to improve the simulation accuracy. Moreover, it is emphasized that both the radiating and ground patches are designed with one elliptic curved edge to help tailor the input impedance to accommodate the $50 \Omega$ source and to help produce smooth transitions from one resonant mode to another across the UWB band [4, 38]. These elliptic curves are constructed following the equation: $(x / \rho)^{2}+(2 y / \mathrm{W})^{2}=1$, where $\rho=1.5 \mathrm{~mm}$ for the radiating patch and $\rho=5.5 \mathrm{~mm}$ for the ground patch. These characteristics ensure a good impedance match over the entire UWB frequency range. It is noted that the presence of the inverted $\mathrm{T}$ slot in the center of radiating patch red-shifts the lower frequency bound and improves the impedance match within the operational frequency range.

TABLE I. The Optimized Design PARAMETERS OF THE UWB ANTENNA (ALl Dimensions ARE IN Millimeters)

\begin{tabular}{|c|c|c|c|c|}
\hline$L=34$ & $L_{1}=18$ & $L_{2}=17.9$ & $L_{3}=1$ & $L_{4}=5$ \\
\hline$L_{5}=1.5$ & $L_{6}=14.6$ & $L_{7}=9.5$ & $L_{8}=2$ & $W=27$ \\
\hline$W_{1}=7.5$ & $W_{2}=5$ & $W_{3}=2.4$ & $W_{4}=2.4$ & Null \\
\hline
\end{tabular}

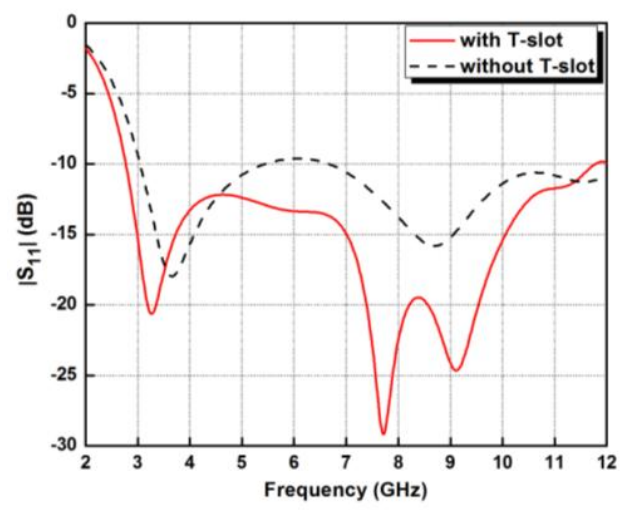

(a)

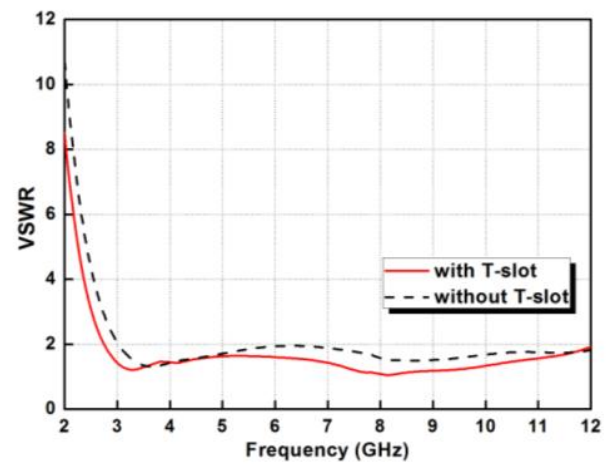

(b)

Fig. 2 Comparisons of the printed monopole UWB antennas with and without the inverted T-slot: (a) $\left|S_{11}\right|$ and (b) VSWR values versus the source frequency.

Fig. 2 displays both the magnitude of the reflection coefficient $\left(\left|\mathrm{S}_{11}\right|\right)$ and the voltage standing wave ratio (VSWR) of the antenna in Fig. 1 with and without the T-slot. From this comparison, it is easily seen that the presence of the T-slot improves the impedance match within the operational frequency range and decreases the lower frequency bound where VSWR < 2 from 3.015 to $2.738 \mathrm{GHz}$, thus exhibiting a $277 \mathrm{MHz}$ red-shift. This aspect of the design engenders a more compact antenna, i.e., the red-shift is equivalent to approximately a $9.2 \%$ reduction in its electrical size. Moreover, the slot shape leaves enough space to introduce a band-notched stub into it.

\section{COMPACT UWB ANTENNA DESIGN WITH TWO INDEPENDENT FREQUENCY-AGILE BAND-NOTCHES}

For the purpose of reducing the dynamical in-band interference in the UWB band, a UWB antenna with two frequency-agile band-notch structures was designed. The baseline monopole was the passive design discussed in Section II. The HFSS model, together with the fabricated prototype, is illustrated in Fig. 3. The optimized design parameters are presented in Table II. In addition, the elliptic curves for the edges are kept unchanged except for a fine tuning of the radiating patch, setting $\rho=1.6 \mathrm{~mm}$.

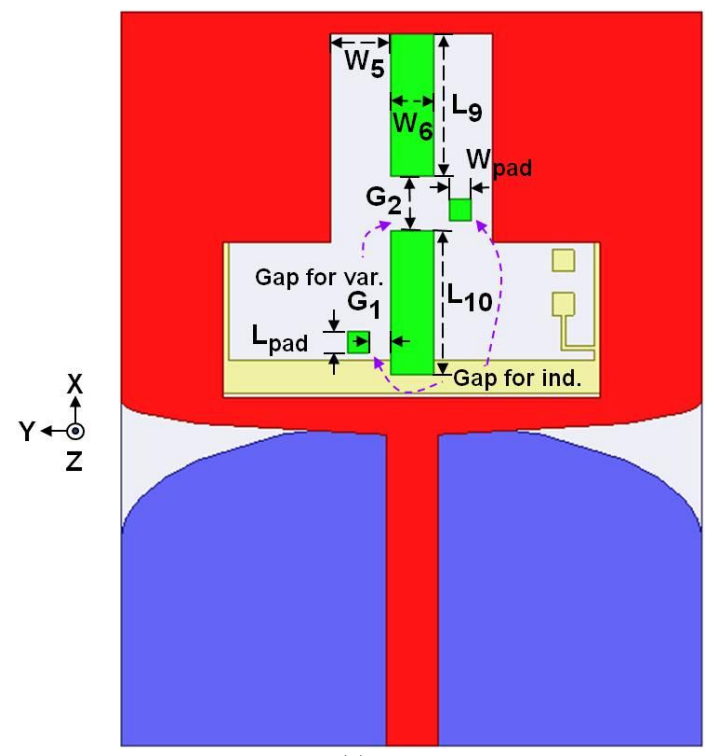

(a)

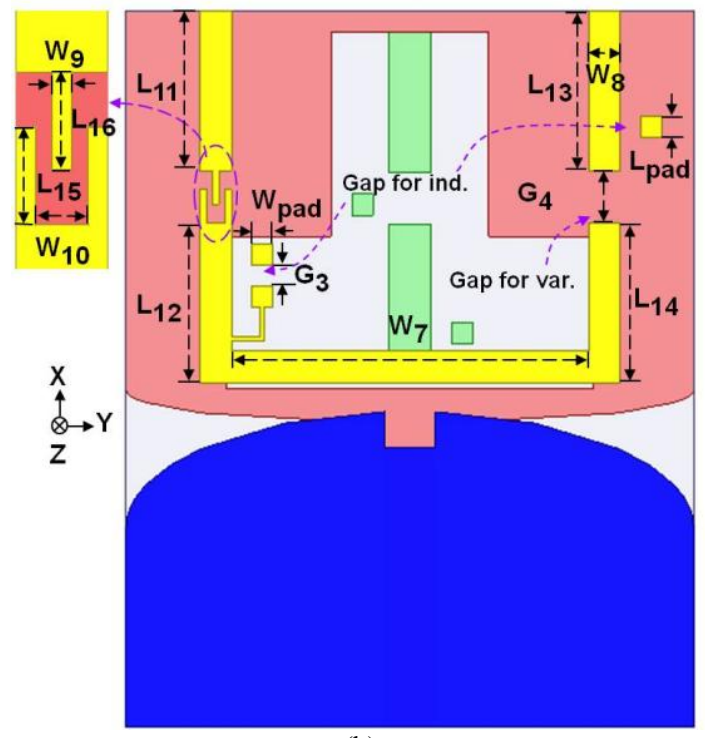

(b) 


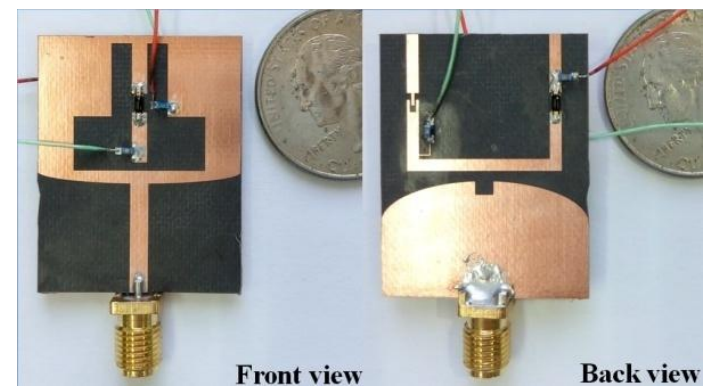

(c)

Fig. 3 Geometry of the UWB antenna with two independent, continuously tunable, frequency-agile band-notches. (a) Top view, (b) bottom view, and (c) fabricated prototype.

On one hand, as is shown in Fig. 3(a), the lower-frequency (below $5 \mathrm{GHz}$ ) band-notch function is accomplished with a cut single straight rectangular strip. This design is simpler and quite different from the one reported previously [4], which realized the low-frequency rejection band using two L-shaped strips placed in parallel. In order to enable the frequency agility of this band-notch element, a gap (with length $\mathrm{G}_{2}$ ) is etched in the middle of strip to leave space for the varactor. Two solder pads (with the same dimension $\mathrm{L}_{\mathrm{pad}} \times \mathrm{W}_{\mathrm{pad}}$ ) are, respectively, positioned close to the strip and to the inner edge of radiating patch. These pads are used for both the RF-blocking coil inductors and as the connection points for the two DC feeder lines.

TABLE II. THE OPTIMIZED DESIGN PARAMETERS OF THE COMPACT UWB ANTENNA WITH TWO INDEPENDENT FREQUENCY-AGILE BAND-NOTCHES (All Dimensions ARE IN Millimeters)

\begin{tabular}{|c|c|c|c|c|}
\hline$L=34$ & $L_{1}=18$ & $L_{2}=17.9$ & $L_{3}=1$ & $L_{4}=7.2$ \\
\hline$L_{5}=1.6$ & $L_{6}=14.5$ & $L_{7}=9.5$ & $L_{8}=1.75$ & $L_{9}=6.65$ \\
\hline$L_{10}=6.65$ & $L_{11}=7.575$ & $L_{12}=7.575$ & $L_{13}=7.575$ & $L_{14}=7.575$ \\
\hline$L_{15}=1.6$ & $L_{16}=1.6$ & $W=27$ & $W_{1}=7.5$ & $W_{2}=5$ \\
\hline$W_{3}=2.4$ & $W_{4}=2.4$ & $W_{5}=2.75$ & $W_{6}=2$ & $W_{7}=17$ \\
\hline$W_{8}=1.5$ & $W_{9}=0.32$ & $W_{10}=0.86$ & $G_{1}=1.3$ & $G_{2}=2.5$ \\
\hline$G_{3}=1.3$ & $G_{4}=2.5$ & $L_{\text {pad }}=1$ & $W_{\text {pad }}=1$ & Null \\
\hline
\end{tabular}

The Aeroflex Metellics MGV 125-20-E28 was selected as the tunable varactor diode. It has a junction capacitance $\left(C_{j}\right)$ in the range of $0.1-1.0 \mathrm{pF}$ and a corresponding tuning reverse bias DC voltage in the range of $18.4-2.0 \mathrm{~V}$ [39]. Its equivalent circuit model is simply described as the RLC series shown in Fig. 4. It includes the diode parasitic inductance $\mathrm{L}_{\mathrm{p}}(0.4 \mathrm{nH})$, the series resistance $\mathrm{R}_{\mathrm{s}}$, and the total capacitance consisting of the parasitic capacitance $\mathrm{C}_{\mathrm{p}}(0.08 \mathrm{pF})$ and the junction capacitance $\mathrm{C}_{\mathrm{j}}(\mathrm{V})$. According to the Aeroflex application note, the value of $\mathrm{R}_{\mathrm{s} 0}$ at $50 \mathrm{MHz}$ can be calculated approximately by the equation $\mathrm{R}_{\mathrm{s} 0}=1 /(2 \pi f c \mathrm{Q})$, where $c$ is the light speed, $\mathrm{Q}$ is the quality factor of the varactor diode (4000), and $f$ is the reference frequency $(50 \mathrm{MHz})$. Since this antenna operates in the UWB range (above $3 \mathrm{GHz}$ ), its $\mathrm{R}_{\mathrm{s}}$ value is approximately $1.3 \times \mathrm{R}_{\mathrm{s} 0}=$ $1.75 \Omega$.

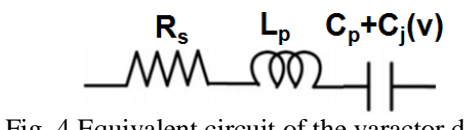

Fig. 4 Equivalent circuit of the varactor diode.
On the other hand, a second band-notch element, i.e., one that would cover the higher frequency portion (above $5 \mathrm{GHz}$ ) of the UWB band, was then sought. It was determined that a U-shaped strip integrated onto the bottom side of the substrate beneath the radiating patch could achieve the desired notch-band properties. The placements in the configuration are shown in Fig. 3(b). Two coil inductors were again applied to isolate the DC bias voltage from the RF signal and prevent damage to the components. Solder pads (with the same dimension $\mathrm{L}_{\mathrm{pad}} \times \mathrm{W}_{\mathrm{pad}}$ ) were incorporated for those inductors.

To further improve the performance, an Aeroflex Metellics MGV 125-22-E28 varactor diode was selected for this design. It has a junction capacitance that changes in the range of $0.2-$ $2.0 \mathrm{pF}$ for the corresponding tuning reverse bias voltage variation from $19.6-2.1 \mathrm{~V}$. Its diode parasitic inductance, series resistance, and parasitic capacitance are $0.4 \mathrm{nH}, 1.28 \Omega$ and $0.08 \mathrm{pF}$, respectively, according to its datasheet and application note [39]. While it provided a comparable capacitance tuning ratio, the reason that this varactor was selected instead of the MGV 125-20-E28 was that it provided twice the maximal junction capacitance value. This property enabled lowering the low end of the notch-band frequencies to be near $5 \mathrm{GHz}$, as will be explained in detail in Section IV.

The arrangement of the two band-notch structures shown in Fig. 3 has three main advantages. First, it efficiently utilizes the limited area available in this already compact configuration. Second, because the operational mechanisms of the two band-notch structures are quite different, they can be continuously tuned independently of each other. In particular, because of the geometry, the mutual coupling between the straight strip and the U-shaped strip is very low, even when the two notch-bands are close to one another. As noted in [3, 43], multiple notch-bands are possible, even when their resonant structures are near to each other, if their mutual coupling is small. Third, both the straight and U-shaped strips are natural DC-blocking structures [44]. Thus, any DC issues are avoided without subdividing any of the components $[22,25]$ or adding any auxiliary elements, such as lumped capacitive elements [30-33] or DC blocking networks [45].

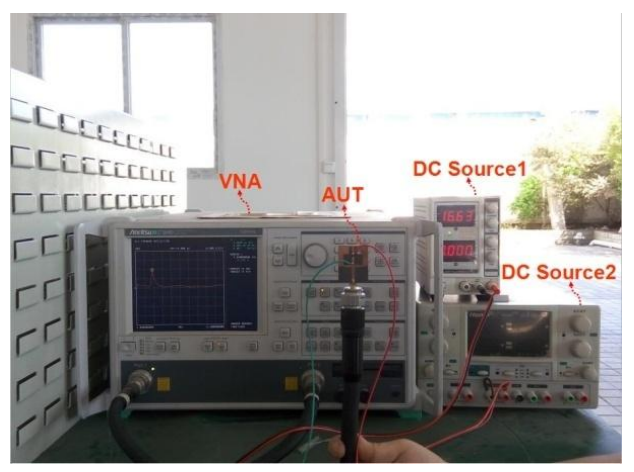

Fig. 5 Experimental setup to measure the antenna performance. The antenna under test (AUT), the VNA and the two DC power sources are shown.

However, it was initially found that there were unavoidable extra resistive losses because there were twice the number of lumped elements (e.g., varactors and inductors) required for the 
two independent band-notch systems. The presence of those losses not only decreased the antenna radiation efficiencies over the rest of the UWB frequency range of UWB band, but they also degraded the rejection levels (i.e., the peak VSWR values) within the notch-band.

In order to alleviate these drawbacks, RF-blocking coil inductors with low values, $47 \mathrm{nH}$, were utilized in the final design because they had low parasitic resistance values. It was found that this choice maintained the antenna efficiency across the UWB frequency range. Because of our use of lumped elements, our frequency-agile approach is more suitable for lower frequency applications rather than millimeter wave ones, such as $60 \mathrm{GHz}$. Furthermore, when compared with similar reported efforts (e.g., [23, 26, 29, 31, 32]), the overall number count of lumped elements required in each of band-notch structure in our design is much smaller. This feature alone simplifies the antenna structure, saving much time in its design, fabrication and measurement.

The UWB antenna was simulated and measured. The VSWR of the fabricated antenna as a function of the excitation frequency was obtained with the measurement system depicted in Fig. 5. It included an Anritsu 37369D vector network analyzer (VNA) and two voltage-stabilized sources.
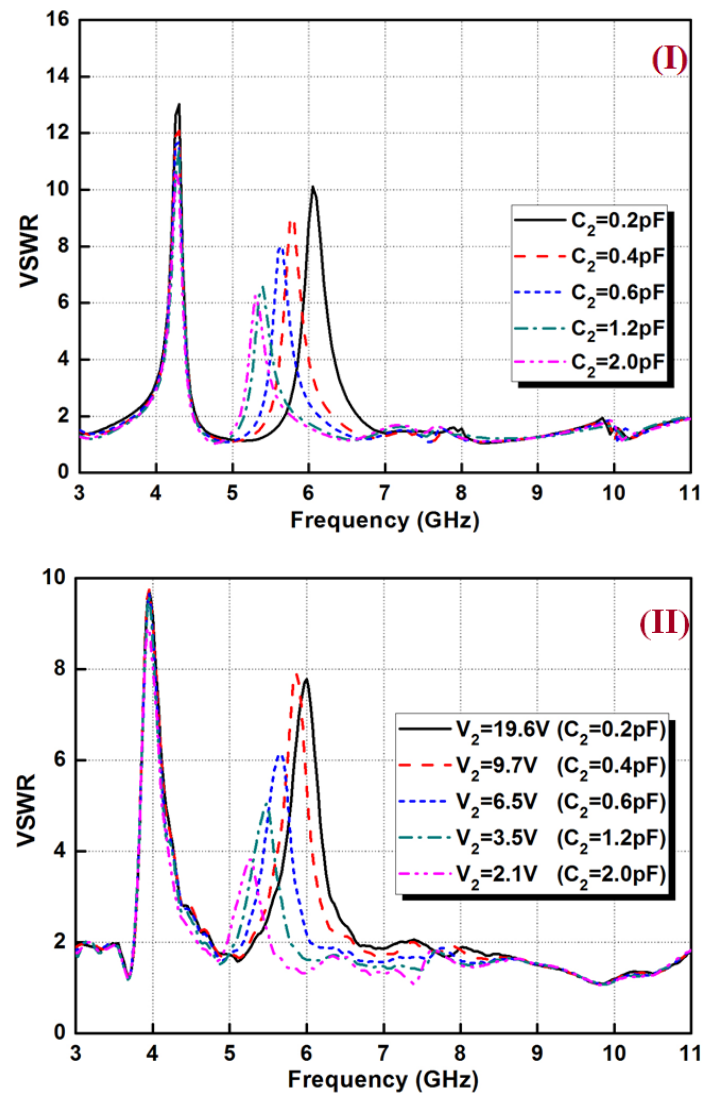

(a)
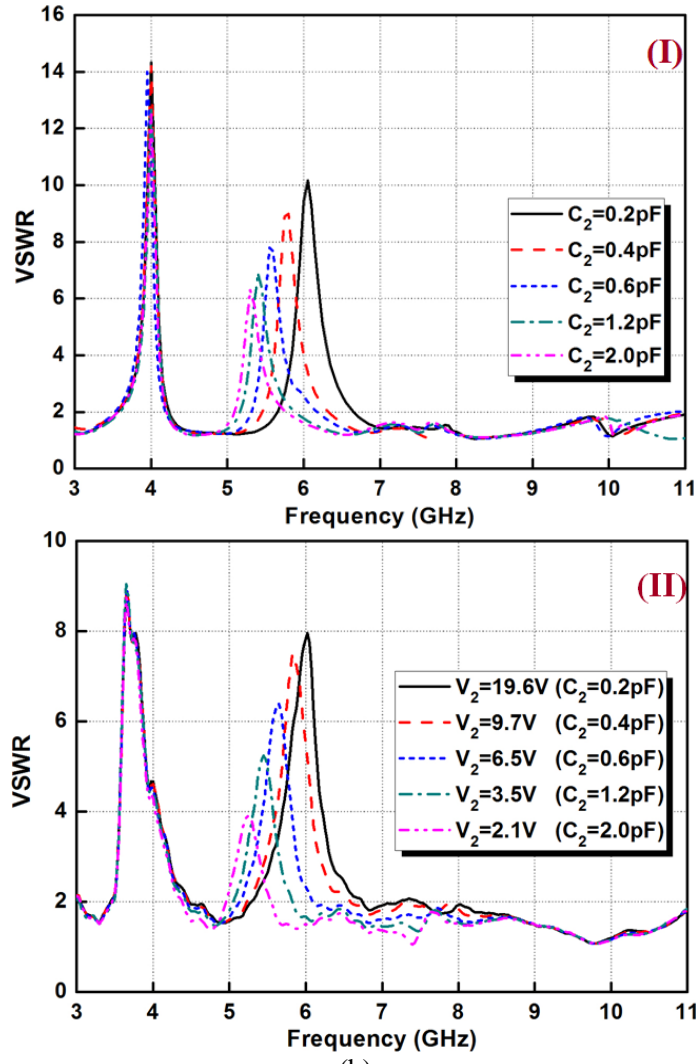

(b)
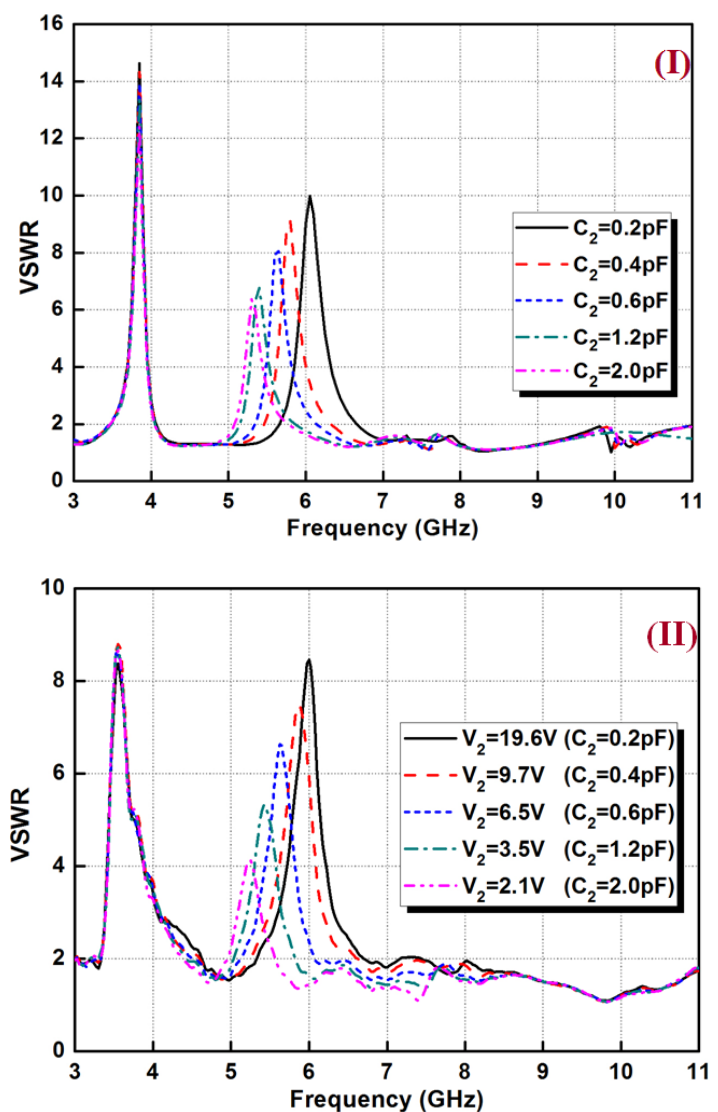

(c) 

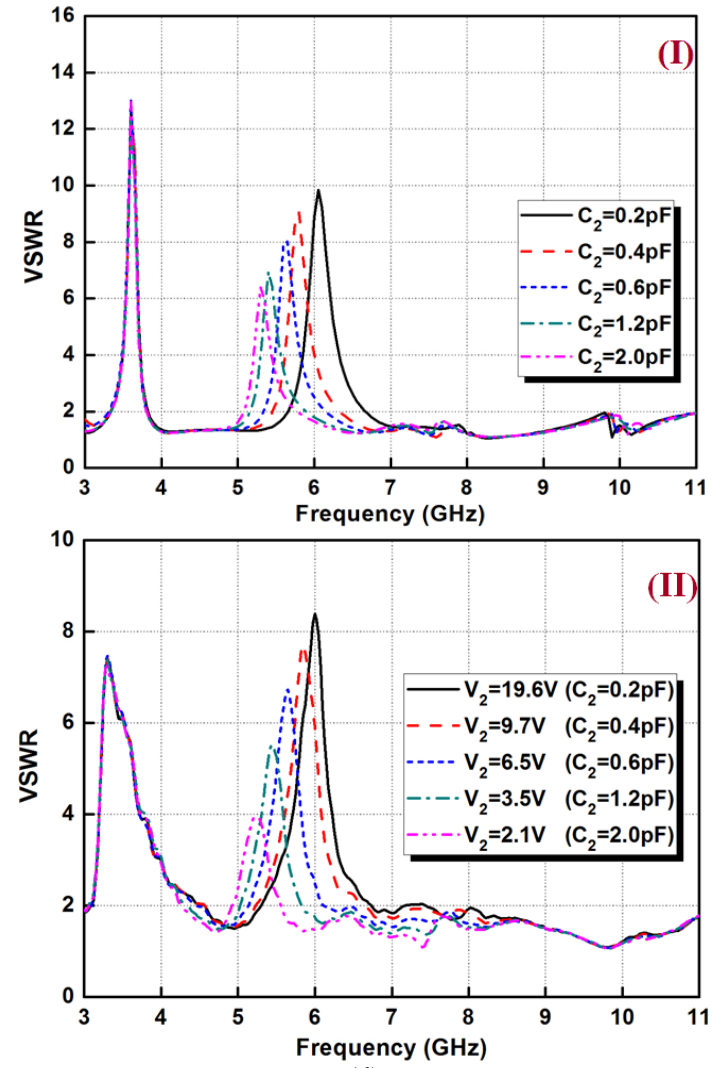

(d)
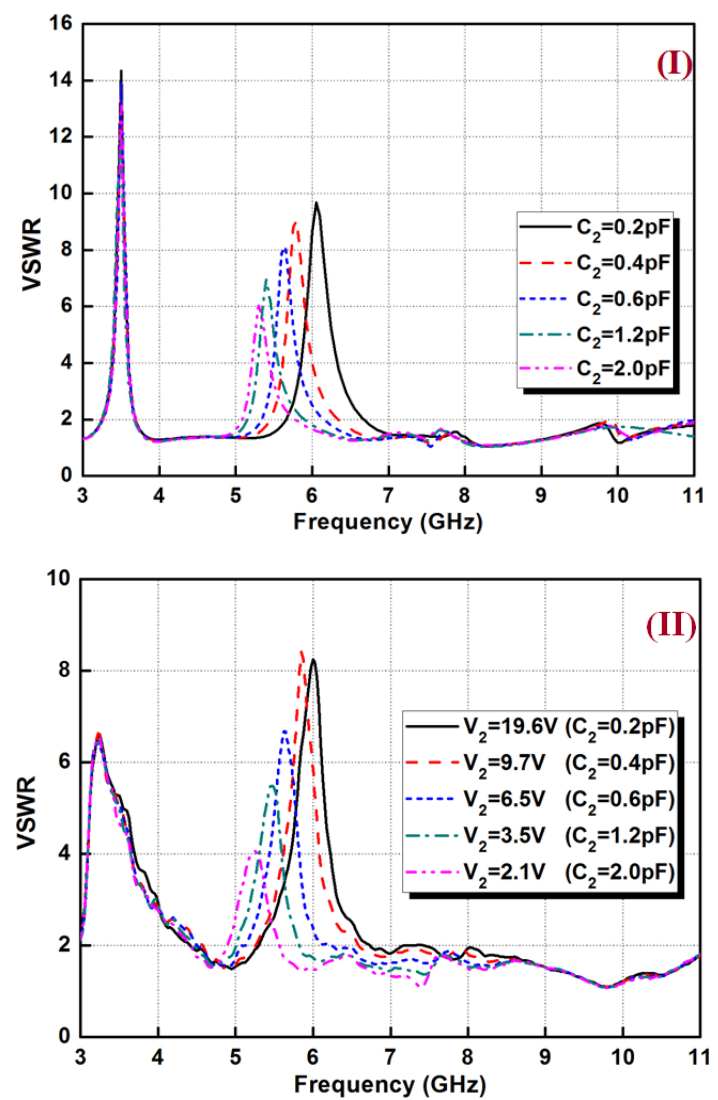

(e)

Fig. 6 The HFSS-predicted (I) and measured (II) VSWR values for the compact UWB antenna with two independent frequency-agile band-notches. The voltages applied to the varactors were varied independently. The results for the effective capacitances of the high frequency band-notch, $\mathrm{C}_{2}$, are provided for each of the effective capacitances of the lower frequency band-notch: (a) $\mathrm{C}_{1}=$ $0.1 \mathrm{pF}$; (b) $\mathrm{C}_{1}=0.2 \mathrm{pF}$; (c) $\mathrm{C}_{1}=0.3 \mathrm{pF}$; (d) $\mathrm{C}_{1}=0.6 \mathrm{pF}$; and (e) $\mathrm{C}_{1}=1.0 \mathrm{pF}$.

The simulated and measured VSWR results are presented and compared in Fig. 6. First, these results demonstrate that both of the frequency-agile band-notch structures exhibited excellent independent, continuous tunability. In particular, the simulated junction capacitance $\mathrm{C}_{1}$ (experimentally applied bias DC voltage $\mathrm{V}_{1}$ ) of the MGV 125-20-E28 varactor diode on the top side of the substrate was set to the values: $0.1 \mathrm{pF}(18.4 \mathrm{~V})$, $0.2 \mathrm{pF}(9.0 \mathrm{~V}), 0.3 \mathrm{pF}(6.3 \mathrm{~V}), 0.6 \mathrm{pF}(3.3 \mathrm{~V}), 1 \mathrm{pF}(2.0 \mathrm{~V})$ in the measurement series while the high-frequency notched band capacitance $\mathrm{C}_{2}$ was held fixed. When the value of $\mathrm{C}_{1}\left(\mathrm{~V}_{1}\right)$ was changed from $0.1 \mathrm{pF}(18.4 \mathrm{~V})$ to $1.0 \mathrm{pF}(2 \mathrm{~V})$, the center frequency of the low-frequency notched band decreased from $4.3 \mathrm{GHz}(3.95 \mathrm{GHz})$ to $3.5 \mathrm{GHz}(3.225 \mathrm{GHz})$, yielding a tunable bandwidth of $0.8 \mathrm{GHz}(0.725 \mathrm{GHz})$, i.e., a $20.5 \%$ $(20.2 \%)$ tunable fractional bandwidth, while the high-frequency notched band remained unchanged. In comparison, the simulated junction capacitance $\mathrm{C}_{2}$ (experimentally applied bias DC voltage $\mathrm{V}_{2}$ ) of the $\mathrm{MGV}$ 125-22-E28 varactor diode on the bottom side of substrate was set to the values: $0.2 \mathrm{pF}(19.6 \mathrm{~V}), 0.4 \mathrm{pF}(9.7 \mathrm{~V}), 0.6 \mathrm{pF}(6.5 \mathrm{~V})$, $1.2 \mathrm{pF}(3.5 \mathrm{~V}), 2.0 \mathrm{pF}(2.1 \mathrm{~V})$ in the measurement series while the low-frequency notched band capacitance $\mathrm{C}_{1}$ was held fixed. When the value of $\mathrm{C}_{2}\left(\mathrm{~V}_{2}\right)$ was changed from $0.2 \mathrm{pF}(19.6 \mathrm{~V})$ to $2.0 \mathrm{pF}(2.1 \mathrm{~V})$, the center frequency of the high-frequency notched band decreased from $6.05 \mathrm{GHz}(6 \mathrm{GHz})$ to $5.3 \mathrm{GHz}$ $(5.25 \mathrm{GHz})$, yielding a tunable coverage of $0.75 \mathrm{GHz}(0.75$ $\mathrm{GHz}$ ), i.e., a $13.22 \%(13.33 \%)$ tunable fractional bandwidth, while the low-frequency notched band remained unchanged.

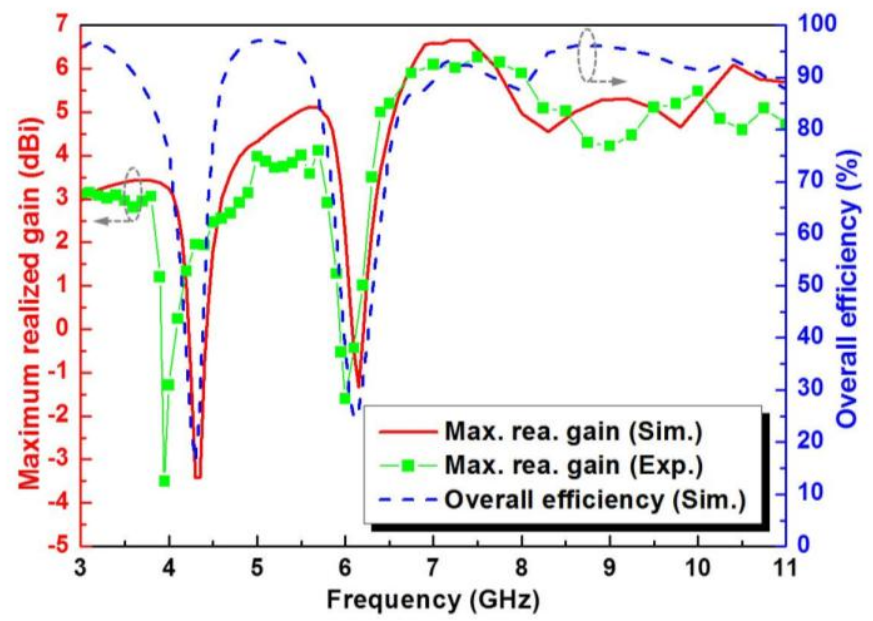

Fig. 7 The maximum realized gain and overall efficiency as a function of the excitation frequency.

It was found in both simulation and measurement that the rejection levels for both band-notch structures, i.e., the amounts that the VSWR was greater than 2, were quite high. Moreover, as observed in the simulated and almost all of the experimental results of Fig. 6, the corresponding notch heights decrease with an increase of either the $\mathrm{C}_{1}$ or $\mathrm{C}_{2}$ values. The simulated (measured) frequency-agile notch-bands covered frequencies from $3.26(2.975)$ to $4.48(4.75) \mathrm{GHz}$ in the low-frequency 
range. This outcome corresponds to a fractional bandwidth of $31.5 \%(46.1 \%)$. The corresponding values in the high-frequency range covered from 5.095 (4.975) to 6.64 (6.625) GHz. This outcome corresponds to a fractional bandwidth of $26.3 \%$ (28.4\%). In total, the measured fractional frequency-agile notched bandwidth was $74.5 \%$. This value is much higher than the ones reported in related work [22-34].

Finally, we arbitrarily selected one case: $\mathrm{C}_{1}=0.1 \mathrm{pF}$ and $\mathrm{C}_{2}=$ $0.2 \mathrm{pF}$ to investigate the radiation performance characteristics numerically and experimentally. These results are compared in Figs. 7 and 8. Fig. 7 provides the antenna peak realized gain and overall efficiency values as a function of the excitation frequency. It is observed that the simulated (measured) gain and efficiency values significantly decrease at the two band-notched frequencies, i.e., around $4.3 \mathrm{GHz}(3.95 \mathrm{GHz})$ and $6.05 \mathrm{GHz}(6 \mathrm{GHz})$. The far-field radiation patterns were measured in an anechoic chamber. The measured results and the relevant simulation values at $3,5,7$ and $9 \mathrm{GHz}$ are shown in Fig. 8. As expected from the antenna geometry, the E-plane patterns are basically monopole-like in all cases, while the $\mathrm{H}$-plane patterns are almost omni-directional. It is noted that the radiation patterns degrade at the higher frequencies because of the presence of higher order operational modes, which has been extensively studied in our previous work [38].

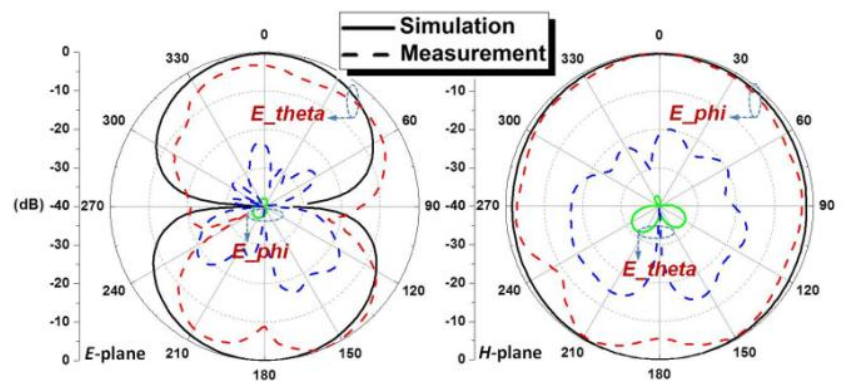

(a)

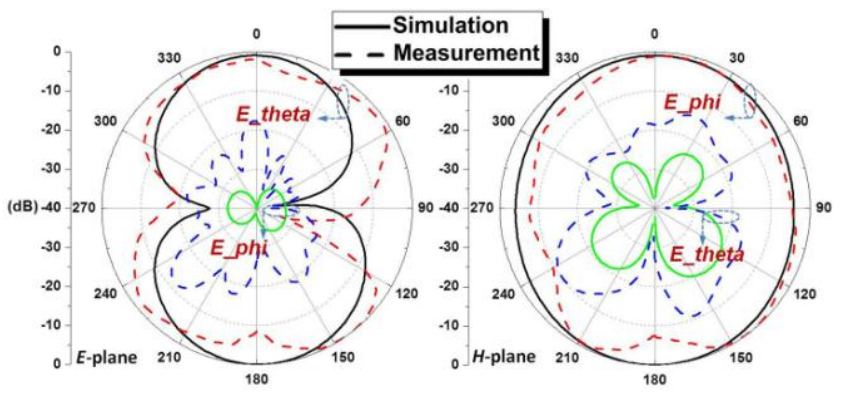

(b)

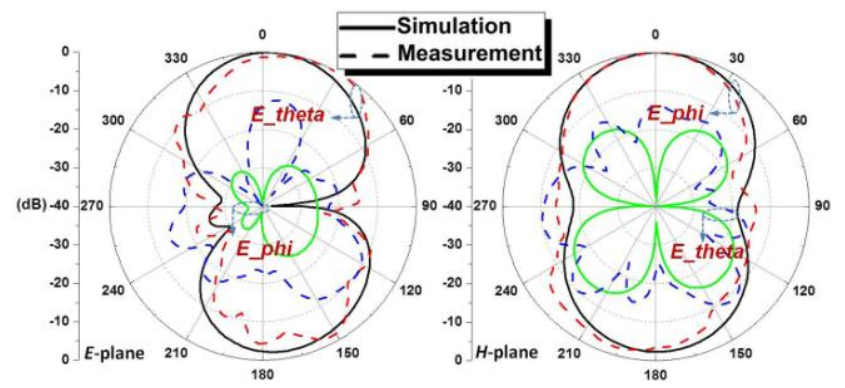

(c)

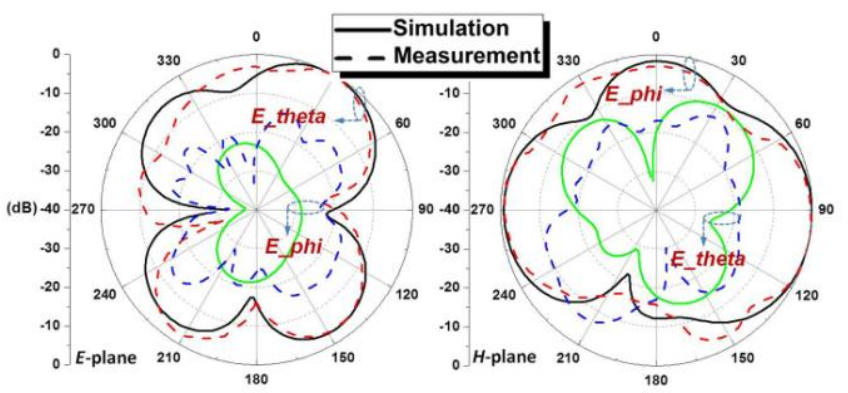

(d)

Fig. 8 Simulated and measured radiation patterns in the $E$ - (ZOX) and $H$ - (ZOY) planes at several frequency points. (a) 3, (b) 5, (c) 7, and (d) $9 \mathrm{GHz}$.

The small differences between the simulated and experimental results were deemed very acceptable. They arose from the presence of the long feed lines in the measurement setup, and the usual unavoidable errors in the fabrication, installation, and measurement processes. It must be mentioned that there was an impact on the impedance match by the presence of the DC feeder lines in the near field of the antenna, especially in the lower frequency range near $3 \mathrm{GHz}$. It was found that the orientation of the feeder lines could not be neglected in those measurements. It was determined by experience that their impact could be minimized effectively by adjusting the feed line orientations relative to the main current flow directions on the radiating and ground patches. The minimum-impact layout of those feed lines is shown in Figs. $3(\mathrm{c})$ and 5.

\section{DISCUSSION}

The design principles and physical mechanisms of the two frequency-agile band-notch structures are described in detail. The individual design features emphasize either or both of the low and high frequency aspects of the antenna's performance characteristics.

\section{A. Low-frequency tunable band-notch function}

The low-frequency tunable band-notch design is different from the approach used in [26]. In that work a single tunable band-notch was achieved by embedding two varactor diodes into a pair of open-loop resonators. In contrast, as indicated in Fig. 3(a), only a simple strip structure and a single varactor are required to obtain the desired tunable band-notch performance. In the same manner, the current design is also simpler than the two L-shaped strips approach reported in [4].

The center frequency of the lower band-notch is determined primarily by both the strip length and the effective capacitance value produced by the varactor. Based on our parametric studies of the strip alone, this center frequency was empirically determined to be:

$$
f_{\text {notch }}=\frac{1}{2 \pi \sqrt{L_{\text {eff }} C_{\text {eff }}}}=\frac{c}{4 L_{\text {strip }} \cdot \sqrt{\varepsilon_{\text {eff }}}}
$$

where $L_{\text {eff }}$ and $C_{\text {eff }}$ are, respectively, the effective inductance and capacitance of the antenna, $c$ is the speed of light, $L_{\text {strip }}$ is the total length of the strip $\left(\mathrm{L}_{9}+\mathrm{L}_{10}\right)$, and $\varepsilon_{\text {eff }} \sim\left(\varepsilon_{r}+1\right) / 2$ is the approximate effective dielectric constant. The center frequency of the band-notch predicted with (1) and its HFSS simulated 
value are summarized in Table III for comparison purposes for different total lengths of the strip.

TABle III. COMPARISONS BETWEen THE THEORETICALly PREDICTED AND SIMULATIONS VALUES OF THE LOWER BAND-NOTCH FREQUENCY

\begin{tabular}{ccc}
\hline$L_{\text {strip }}(\mathrm{mm})$ & Theoretical frequency $(\mathrm{GHz})$ & Simulated frequency $(\mathrm{GHz})$ \\
\hline 14 & 4.235 & 4.205 \\
\hline 15 & 3.953 & 3.860 \\
\hline 16 & 3.706 & 3.550 \\
\hline
\end{tabular}

We note that the process of integrating the varactor into the gap of the strip in Fig. 3(a) is equivalent to introducing an additional tunable capacitance $\mathrm{C}_{1}$ into the band-notch structure that increases its overall $C_{\text {eff. }}$ This effect not only lowered $f_{\text {notch }}$, but it also enabled the tuning of $f_{\text {notch }}$ in the lower-frequency portion of the UWB band, as illustrated in Fig. 6.

\section{B. High-frequency tunable band-notch function}

Physically, the U-shaped structure acts as a near-field resonant parasitic (NFRP) element [4, 40]. Its design principles and an approximate expression to determine its band-notched frequency were reported in $[41,42]$. By being placed directly beneath the radiating patch, the U-shaped structure is capacitively-coupled to it. This additional capacitance helps not only to red-shift the lower bound of the overall UWB bandwidth of this antenna, but it also helps create the desired band-notch.

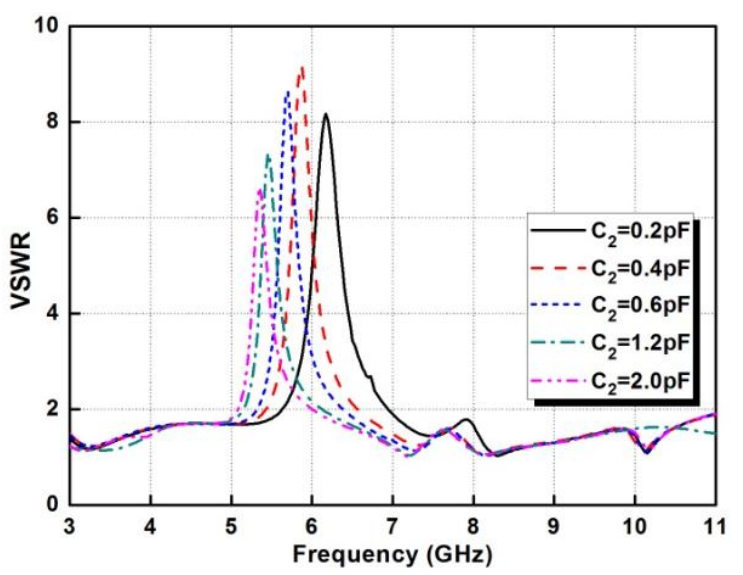

(a)

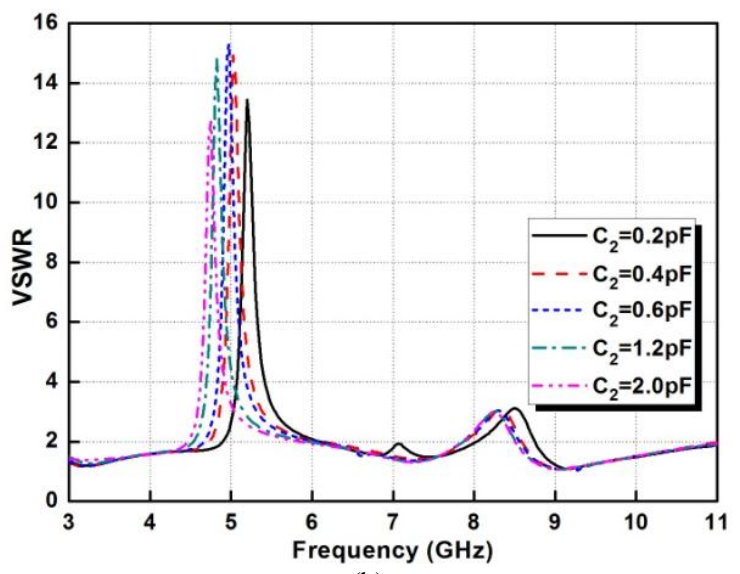

(b)
Fig. 9 The VSWR values as a function of frequency for the single high-frequency tunable band-notched UWB antenna. (a) with the interdigitated structure, and (b) without the interdigitated structure.

As is shown in Fig. 3(b), a rectangular cut was etched on the right leg of the U-shaped structure to allow for embedding the varactor diode into it. On its left leg, an interdigitated capacitive structure was inserted. It not only suppresses the resonance arising from the second natural mode of the U-shaped resonator, but it also increases the frequency-agile bandwidth of the notched band. To clarify this phenomenon, the antenna with a single high-frequency tunable band-notch (i.e., with the U-shaped resonator), and with and without the interdigitated structure was simulated and compared.

These simulated VSWR values are presented in Fig. 9. As is shown in Fig. 9(a), by changing the effective value of the varactor diode $\mathrm{C}_{\mathrm{j}}(\mathrm{V})$ from 0.2 to $2 \mathrm{pF}$, the center frequency of the rejection band of the antenna with the interdigital structure is tuned from 6.175 to $5.35 \mathrm{GHz}$. As a consequence, its frequency-agile notched band, where the VSWR > 2, is in the range from 6.950 to $5.080 \mathrm{GHz}$, i.e., a $31.1 \%$ fractional bandwidth was demonstrated. Comparing Figs. 9(a) and (b), one readily observes that the antenna without the interdigital structure exhibits an impedance mismatch around $8.5 \mathrm{GHz}$ (where the peak VSWR values are greater than 3). Moreover, it increases the frequency-agile bandwidth of the notched band. As is shown in Fig. 9(b), the center frequency of the rejection band is shifted only from 5.2 to $4.75 \mathrm{GHz}$ for the same $\mathrm{C}_{\mathrm{j}}(\mathrm{V})$ tuning range, i.e., a shift of only $0.45 \mathrm{GHz}$, which is $54.5 \%$ of that shown in Fig. 9(a) when the interdigitated structure is present. In addition, it should be noted when comparing these results that the presence of the interdigitated structure has an additional side effect, i.e., it blue-shifts the center frequency of the band-notch around $0.6 \mathrm{GHz}$. This also re-emphasizes why the MGV 125-22-E28 varactor was selected for this design instead of the MGV 125-20-E28; it facilitates a red-shift of the lowest frequency bound of the notch-band closer to $5 \mathrm{GHz}$.

\section{CONCLUSIONS}

A compact planar UWB antenna with two independent, continuously tunable band-notches was investigated numerically and experimentally. On the top side of the printed UWB monopole antenna substrate, a cut straight rectangular strip was embedded into the inverted $\mathrm{T}$-slot of its radiating patch to achieve the first band-notch, which occurs in the lower portion of the UWB frequency band. An interdigitated, cut U-shaped parasitic element was placed directly beneath the radiating patch on the bottom side to realize the second band-notch, which occurs in the higher portion of the UWB frequency band. The interdigitated component was introduced to suppress the impact of higher-order modes. Varactors were inserted into the cuts of each of the band-notch structures to enable their continuous frequency-agile tuning. The antenna was designed, optimized and tested. Good agreement between the simulated and measured results was obtained.

The final design incorporated a minimal number of lumped components. It was demonstrated that each band-notch was independently controllable and independently covered the 
lower and upper portions of the UWB band. The overall realized frequency-agile fractional bandwidth was as high as $74.5 \%$. Reasonably flat realized gain values and relatively stable radiation patterns were demonstrated across the UWB band. Consequently, the realized compact printed UWB antenna with two continuously-tunable independently -addressable band-notches may be suitable for a variety of cognitive radio applications.

\section{References}

[1] I. Y. Immoreev, "Practical applications of UWB technology," IEEE A\&E Systems Mag., vol. 25, no. 2, pp. 36 - 42 , Feb. 2010

[2] G. Adamiuk, T. Zwick, and W. Wiesbeck, "UWB antennas for communication systems," Proc. IEEE, vol. 100, no. 7, pp. 2308-2321, Jul. 2012.

[3] M.-C. Tang, S. Xiao, T. Deng, D. Wang, J. Guan, B. Wang, and G.-D. Ge, "Compact UWB antenna with multiple band-notches for WiMAX and WLAN," IEEE Trans. Antennas and Propag., vol. 59, no. 4, pp.1372-1376, Apr. 2011.

[4] C.-C. Lin, P. Jin, and R. W. Ziolkowski, "Single, dual and tri-band-notched Ultrawideband (UWB) antennas using capacitively loaded loop (CLL) resonators," IEEE Trans. Antennas and Propag., vol. 60, no. 1, pp.102-109, Jan. 2012.

[5] Y. Sung, "Triple band-notched UWB planar monopole antenna using a modified H-shaped resonator," IEEE Trans. Antennas and Propag., vol. 61, no. 2, pp. 953 - 957, Feb. 2013.

[6] S. M. Abbas, Y. Ranga, A. K. Verma, and K. P. Esselle, "A simple Ultra wideband printed monopole antenna with high band rejection and wide radiation patterns," IEEE Trans. Antennas and Propag., vol. 62, no. 9, pp. 4816-4820, Sep. 2014.

[7] A. Petosa, "An overview of tuning techniques for frequency-agile antennas," IEEE Antennas Propag. Mag., 54 (2012), 271-296.

[8] V. A. Shameena, M.N. Suma, K. R. Rohith, P.C. Bybi, and P. Mohanan, "Compact ultra-wideband planar serrated antenna with notch band ON/OFF control," Electron. Lett., vol. 42, no. 23, pp. 1323 - 1324, Nov. 2006.

[9] A. Valizade, C. Ghobadi, J. Nourinia, and M. Ojaroudi, "A novel design of reconfigurable slot antenna with switchable band notch and multiresonance functions for UWB applications," IEEE Antennas Wireless Propag. Lett., vol. 11, pp. 1166- 1169, 2012.

[10] A.A. Kalteh, G.R. DadashZadeh, M. Naser-Moghadasi, and B.S. Virdee, "Ultra-wideband circular slot antenna with reconfigurable notch band function," IET Microw. Antennas Propag., Vol. 6, Iss. 1, pp. 108-112, 2012.

[11] N. Ojaroudi, and M. Ojaroudi, "A novel design of reconfigurable small monopole antenna with switchable band notch and multiresonance functions for UWB applications," Microw. Opt. Technol. Lett., vol. 55, no. 3, pp. 652-656, Mar. 2013.

[12] C. M. Dikmen, S. Çimen, and G. Çakır, "A novel Ultrawideband antenna with switchable notch band," Microw. Opt. Technol. Lett., vol. 55, no. 7, pp. 1461-1466, Jul. 2013.

[13] N. Tasouji, J. Nourinia, C. Ghobadi, and F. Tofigh, "Novel printed UWB slot antenna with reconfigurable band-notch characteristics," IEEE Antennas Wireless Propag. Lett., vol. 12, pp. 922- 925, 2013.

[14] Y. Li, W. Li, and R. Mittra, "A compact CPW-fed circular slot antenna with reconfigurable dual band-notch characteristics for UWB communication applications," Microw. Opt. Technol. Lett., vol. 56, no. 2, pp. 465-468, Feb. 2014.

[15] B. Badamchi, J. Nourinia, C. Ghobadi, and A. V. Shahmirzadi, "Design of compact reconfigurable ultra-wideband slot antenna with switchable single/dual band notch functions," IET Microw. Antennas Propag., vol. 8, Iss. 8, pp. 541-548, 2014.

[16] S. Nikolaou, N. D. Kingsley,G. E. Ponchak, J. Papapolymerou, and M. M. Tentzeris, "UWB elliptical monopoles with a reconfigurable band notch using MEMS switches actuated without bias lines," IEEE Trans. Antennas and Propag., vol. 57, no. 8, pp. 2242-2251, Aug. 2009.

[17] D. E. Anagnostou, M. T. Chryssomallis, B. D. Braaten,, J. L. Ebel, and N. Sepúlveda, "Reconfigurable UWB antenna with RF-MEMS for on-demand WLAN rejection," IEEE Trans. Antennas and Propag., vol. 62, no. 2, pp.602-608, Feb. 2014.
[18] T. Wu, H. Bai, P. Li, X.-W. Shi "A simple planar monopole UWB slot antenna with dual independently and reconfigurable band-notched characteristics," International Journal of $R F$ and Microwave Computer-Aided Engineering, vol. 24, no. 6, pp. 706-712, Nov. 2014.

[19] P. Lotfi, M. Azarmanesh, and S. Soltani, "Rotatable dual band-notched UWB/triple-band WLAN reconfigurable antenna," IEEE Antennas Wireless Propag. Lett., vol. 12, pp. 104- 107, 2013.

[20] D. Zhao, L. Lan, Y. Han, F. Liang, Q. Zhang, and B.-Z. Wang, "Optically controlled reconfigurable band-notched UWB antenna for cognitive radio applications," IEEE Photon. Technol. Lett., vol. 26, no. 21, pp. 21732176, Nov. 2014.

[21] S. H. Zheng, X. Liu and M. M. Tentzeris, "Optically controlled reconfigurable band-notched UWB antenna for cognitive radio systems," Electron. Lett., vol. 50, no. 21, pp. 1502-1504, Oct. 2014.

[22] E. Antonino-Daviu, M. Cabedo-Fabrés, M. Ferrando-Bataller, and A. Vila-Jimenez, "Active UWB antenna with tunable band-notched behavior," Electron. Lett., vol. 43, no. 18, pp. 959 - 960, Aug. 2007.

[23] W.-S. Jeong, D.-Z. Kim, W.-G. Lim, and J.-W. Yu, "Tunable band-botched Ultra wideband planar monopole antenna," Microw. Opt. Technol. Lett., vol. 51, no. 12, pp. 2829-2832, Dec. 2009.

[24] Z. H. Hu, P.S. Hall, J. R. Kelly and P. Gardner, "UWB pyramidal monopole antenna with wide tunable band-notched behavior," Electron. Lett., vol. 46, no. 24, pp. 1588 - 1590, Nov. 2010.

[25] E. Antonino-Daviu, M. Cabedo-Fabrés, M. Ferrando-Bataller, and V. M. R. Peñarrocha, "Modal analysis and design of band-notched UWB planar monopole antennas," IEEE Trans. Antennas and Propag., vol. 58, no. 5, pp. 1457- 1467, May 2010.

[26] T. Li, H. Zhai, L. Li, C. Liang, and Y. Han, "Compact UWB antenna with tunable band-notched characteristic based on microstrip open-loop resonator," IEEE Antennas Wireless Propag. Lett., vol. 11, pp. 15841587, 2012.

[27] E. Erfani, J. Nourinia, C. Ghobadi, M. Niroo-Jazi, and T. A. Denidni, "Design and implementation of an integrated UWB/reconfigurable-slot antenna for cognitive radio applications," IEEE Antennas Wireless Propag. Lett., vol. 11, pp. 77-80, 2012.

[28] I. T. E. Elfergani, R. A Abd-Alhameed, C. H. See, S. M. R. Jones, and P. S. Excell, "A compact design of tunable band-notched Ultrawideband antenna," Microw. Opt. Technol. Lett., vol. 54, no. 7, pp. 1642-1644, Jul. 2012.

[29] S. Loizeau, and A. Sibille, "Reconfigurable ultra-wide band monopole antenna with a continuously tunable band notch," IET Microw. Antennas Propag., vol. 8, iss. 5, pp. 346-350, 2014.

[30] S. A. Aghdam, "A novel UWB monopole antenna with tunable notched behavior using varactor diode," IEEE Antennas Wireless Propag. Lett., vol. 13 pp. 1243- 1246, 2014.

[31] I. T. E. Elfergani, A. S. Hussaini, C. H. See, R. A. Abd-Alhameed, N. J. McEwan, S. Zhu, J. Rodriguez, and R. W. Clarke, "Printed monopole antenna with tunable band-notched characteristic for use in mobile and Ultra-wide band applications," International Journal of $R F$ and Microwave Computer-Aided Engineering, Vol. 25, No. 5, pp. 403-412, Jun. 2015

[32] J. Malik, P. K. Velalam, and M. V. Kartikeyan, "Continuously tunable band-notched ultrawideband antenna," Microw. Opt. Technol. Lett., vol. 57, no. 4, pp. 924-928, Apr. 2015.

[33] M. Nouri, and S. A. Aghdam, "Reconfigurable UWB antenna with electrically control for triple on-demand rejection bandwidth," Microw. Opt. Technol. Lett., vol. 57, no. 8, pp. 1894- 1897, Aug. 2015.

[34] B. Rahmati, and H.R. Hassani, "Wideband planar plate monopole antenna with dual tunable notch," Electron. Lett., vol. 46, no. 7, pp. 480 - 481, Apr. 2010.

[35] S. Haykin, "Cognitive radio: Brain-empowered wireless communications," IEEE J. Sel. Areas Commun., vol. 23, no. 2, pp. 201-220, Feb. 2005.

[36] I. F. Akyildiz, W. Y. Lee, M. C. Vuran, and S. Mohanty, "A survey on spectrum management in cognitive radio networks," IEEE Commun. Mag., vol. 46, no. 4, pp. 40-48, Apr. 2008.

[37] ANSYS/ANSOFT High Frequency Structure Simulation (HFSS), ver. 13.0, ANSYS Corp. [Online]. Available at www.ansoft.com.

[38] M.-C. Tang, R. W. Ziolkowski, and S. Xiao, "Compact hyper-band printed slot antenna with stable radiation properties," IEEE Trans. Antennas and Propag., vol. 62, no. 6, pp. 2962-2969, Jun. 2014.

[39] http://ams.aeroflex.com/Metelics/pdfiles/MGV_Series_Hyperabrupt_A1 7041.pdf.

[40] R. W. Ziolkowski, P. Jin, and C.-C. Lin, "Metamaterial-inspired 
engineering of antennas," Proc. IEEE, vol. 99, no. 10, pp. 1720-1731, Oct. 2011.

[41] R. Zaker, C. Ghobadi, and J. Nourinia, "Bandwidth enhancement of novel compact single and dual band-notched printed monopole antenna with a pair of L-shaped slots," IEEE Trans. Antennas and Propag., vol. 57, no. 12, pp.3978-3983, Dec. 2009.

[42] D.-Z. Kim, W.-I. Son, W.-G. Lim, H.-L. Lee, and J.-W. Yu, "Integrated planar monopole antenna with microstrip resonators having band-notched characteristics," IEEE Trans. Antennas and Propag., vol. 58, no. 9, pp.2837-2842, Sep. 2010.

[43] K. S. Ryu, and A. A. Kishk, "UWB antenna with single or dual band-notches for lower WLAN band and upper WLAN band," IEEE Trans. Antennas and Propag., vol. 7, no. 12, pp.3942-3950, Dec. 2009.

[44] M.-C. Tang, R. W. Ziolkowski, S. Xiao, M. Li, and J. Zhang, "Frequency-agile, efficient, near-field resonant parasitic monopole antenna," IEEE Trans. Antennas and Propag., vol. 62, no. 3, pp. 1479 1483, Mar. 2014.

[45] M. Li, S.-Q. Xiao, Z. Wang, and B.-Z. Wang, "Compact surface-wave assisted beam-steerable antenna based on HIS," IEEE Trans. Antennas and Propag., vol. 62, no. 7, pp.3511-3519, Jul. 2014.

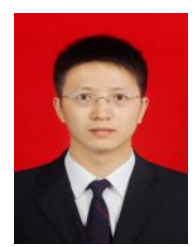

Ming-Chun Tang (S'12-M'13-SM'16) received the B. S. degree in physics from the Neijiang Normal University, Neijiang, China, in 2005 and the $\mathrm{Ph}$. D. degree in radio physics from the University of Electronic Science and Technology of China (UESTC), in 2013. From August 2011 to August 2012, he was also with the Department of Electrical and Computer Engineering, The University of Arizona, Tucson, AZ, USA, as a Visiting Scholar. He is currently an Assistant Professor in the College of Communication Engineering, Chongqing University, China. His research interests include electrically small antennas, RF circuits, metamaterial designs and their applications.

Prof. Tang was a recipient of the Best Student Paper Award in the 2010 International Symposium on Signals, Systems and Electronics (ISSSE2010) held in Nanjing, China. He is serving as a reviewer for IEEE/IET journals including the IEEE Transactions on Microwave Theory and Techniques, IEEE Transactions on Antennas and Propagation, IEEE Antennas and Wireless Propagation Letters, IEEE Antennas and Propagation Magazine, IET Microwaves, Antennas \& Propagation, and Electronics Letters.

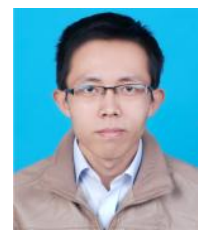

Hao Wang received the B.S. degree in communication engineering from the Lanzhou University (LZU), Lanzhou, China, in 2014.He is currently pursuing the M.S. degree in electronic science and technology at Chongqing University, Chongqing, China.

His research interests include electrically small antennas, planar antennas and arrays.

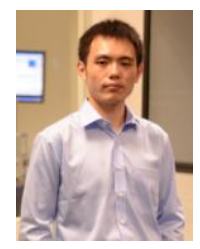

Tianwei Deng (S'12) received the B.S. degree from the University of Electronics Science and Technology of China (UESTC), Chengdu, China, in 2010 and the M.Eng degree from the Nanyang Technological University (NTU), Singapore, in 2012. He is working toward the Ph.D degree at the Department of Electrical and Computer Engineering, National University of Singapore (NUS).

His research interests include metamaterials, absorber/reflector and on-chip antennas.

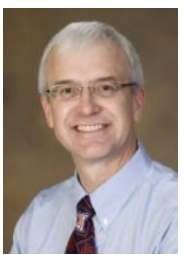

Richard W. Ziolkowski (M'87-SM'91-F'94) received his Sc.B. degree in physics, magna cum laude with honors, from Brown University (1974), and his M.S. (1975) and $\mathrm{Ph} . D$. (1980) degrees in physics from the University of Illinois at Urbana-Champaign. He is the Litton Industries John M. Leonis Distinguished Professor in the Department of Electrical and Computer Engineering at the University of Arizona. He also is a Professor in the College of Optical Sciences at the University of Arizona. He was awarded an Honorary Doctorate, Doctor Technish Honoris Causa, from the Technical University of Denmark
(DTU) in 2012. He was the Computational Electronics and Electromagnetics Thrust Area Leader in the Engineering Research Division at the Lawrence Livermore National Laboratory before joining the University of Arizona in 1990. He was the 2014-2015 Australian DSTO Fulbright Distinguished Chair in Advanced Science and Technology.

Prof. Ziolkowski is a Fellow of both the Institute of Electrical and Electronics Engineers (IEEE) and the Optical Society of America (OSA). He served as the President of the IEEE Antennas and Propagation Society in 2005. $\mathrm{He}$ is also actively involved with the URSI, OSA and SPIE professional societies. His research interests include the application of new mathematical and numerical methods to linear and nonlinear problems dealing with the interaction of electromagnetic and acoustic waves with complex linear and nonlinear media, as well as metamaterials, metamaterial-inspired structures, and applications-specific configurations. 